\title{
Coronary artery bypass grafting in a 26 -year-old man with total occlusion of the left main coronary artery related to Behçet disease
}

\author{
Gökhan İpek, MD, Suat Nail Ömeroğlu, MD, Denyan Mansuroğlu, MD, Kaan Kırali, MD, Kemal Uzun, MD, and \\ Mesut Şişmanoğlu, MD, Istanbul, Turkey
}

$\mathrm{T}$ otal obstruction of the left main coronary artery frequently results in sudden death, and only few patients survive to undergo diagnostic evaluation or treatment. ${ }^{1}$ Coronary artery bypass grafting $(\mathrm{CABG})$ is considered to be the therapy of choice for this condition. Although CABG is rarely performed in patients with Behçet disease, postoperative pseudoaneurysm formation is one of the most serious complications. ${ }^{2}$

\section{Clinical Summary}

A 26-year-old-man with Behçet disease, diagnosed 3 years earlier, was admitted to our hospital with severe chest pain (Canadian

\footnotetext{
From the Division of Cardiovascular Surgery, Koşuyolu Heart and Research Hospital, Istanbul, Turkey.

Received for publication March 16, 2001; accepted for publication April 19, 2001.

Address for reprints: Gökhan İpek, MD, Koşuyolu Heart and Research Hospital, Kadıköy, 81020 Istanbul, Turkey (E-mail: kosuyolu@ superonline. com).

J Thorac Cardiovasc Surg 2001;122:1247-9

Copyright (C) 2001 by The American Association for Thoracic Surgery

$0022-5223 / 2001 \$ 35.00+0 \quad \mathbf{1 2 / 5 4} / \mathbf{1 1 6 5 4 9}$

doi:10.1067/mtc.2001.116549
}

Cardiovascular Society class III). The diagnosis of Behçet disease was based on oral aphtha and genital ulcers accompanied by relapsing iritis. The only cardiac risk factor was smoking. He was receiving only azathioprine. No signs of myocardial infarction were found on the electrocardiogram. Coronary arteriography showed total occlusion of the left main coronary artery, a right dominant coronary anatomy, and well-developed right-to-left collaterals (Figures 1 and 2). Left ventricular function was within normal limits. The echocardiographic study also showed no abnormalities. Thallium 201 scintigraphy showed anteroapical ischemia. A whole body computed tomographic scan failed to reveal any additional findings. C-reactive protein $(3.2 \mathrm{mg} / \mathrm{dL})$ and erythrocyte sedimentation rate $(78 \mathrm{~mm}$ per hour) were elevated, suggesting an ongoing inflammatory condition. The rest of the biochemical and hemographic results were within normal limits. A regimen of oral corticosteroids was begun, in addition to azathioprine. Subsequently, C-reactive protein decreased to normal levels and erythrocyte sedimentation rate decreased to below $10 \mathrm{~mm}$ per hour. However, the therapy was continued throughout and after the operation.

At operation, the pericardium was adherent to the heart, possibly related to complications of a previous episode of pericarditis. The left anterior descending artery was thin and fragile. Although we had planned to operate on the beating heart, we had to switch to an on-pump procedure as a result of the aforementioned rea- 


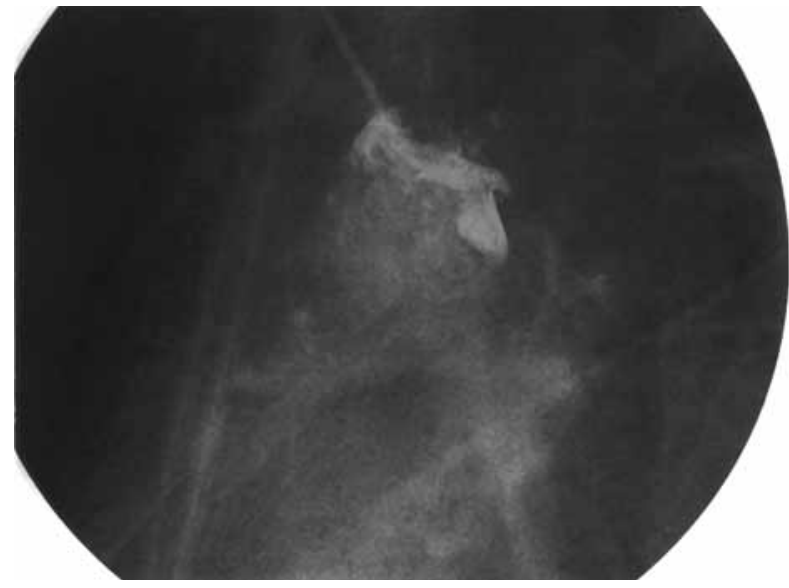

Figure 1. Preoperative coronary arteriogram showed total occlusion of the left main coronary artery.

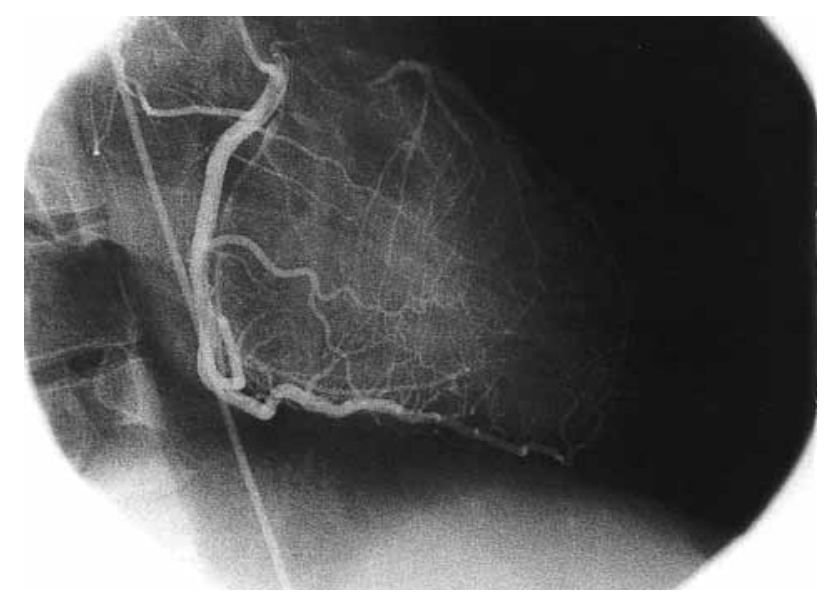

Figure 2. Preoperative coronary arteriogram showed a right dominant coronary anatomy and well-developed right-to-left collaterals.

sons. The left internal thoracic artery was anastomosed to a welldeveloped diagonal branch. The arteries in the circumflex system were nongraftable. The left anterior descending artery was anastomosed with a saphenous vein graft. The operation was completed uneventfully after a 2-vessel bypass.

His condition improved after the operation and remained stable 2 months later. However, a follow-up angiogram revealed that the saphenous vein-left anterior descending artery anastomosis was occluded and a pseudoaneurysm had developed in the ascending aorta. On the other hand, the left internal thoracic artery-diagonal branch anastomosis was patent and was filling the entire left coronary system (Figure 3 ). A magnetic resonance angiogram showed a saccular pseudoaneurysm, $25 \times 22 \times 21 \mathrm{~mm}$ in dimension, located in the right anterolateral ascending aorta, $1.5 \mathrm{~cm}$ above the right coronary artery ostium (Figure 4). The patient is followed up with magnetic resonance imaging studies at 3-month intervals and will be reoperated on if the dimensions of the pseudoaneurysm increase.

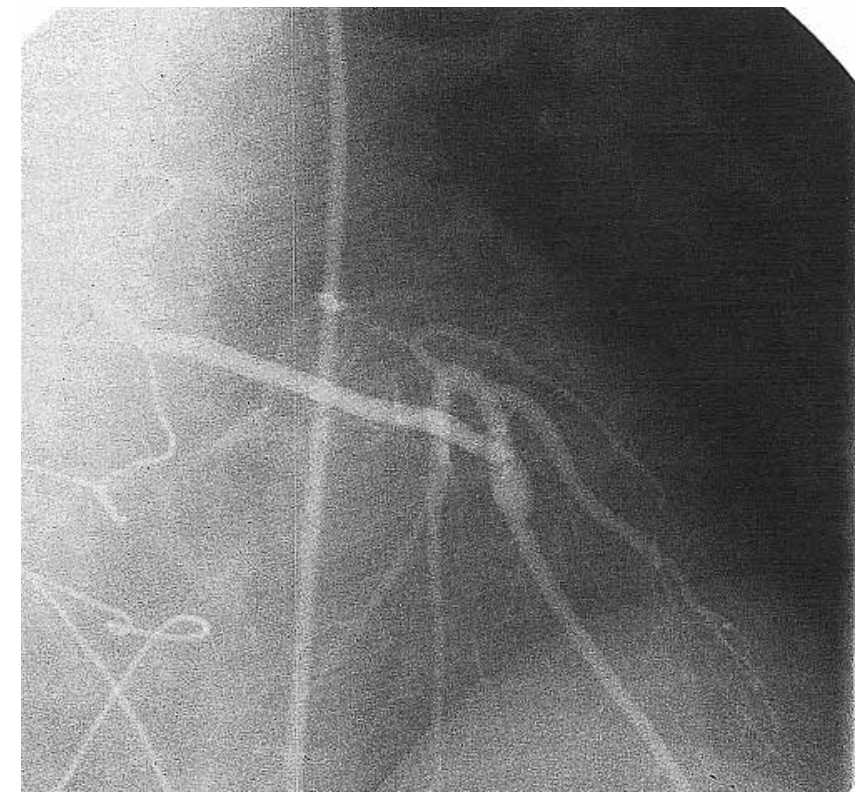

Figure 3. Follow-up angiogram revealed that the left internal thoracic artery-to-diagonal branch anastomosis was patent and was filling the entire left coronary system.

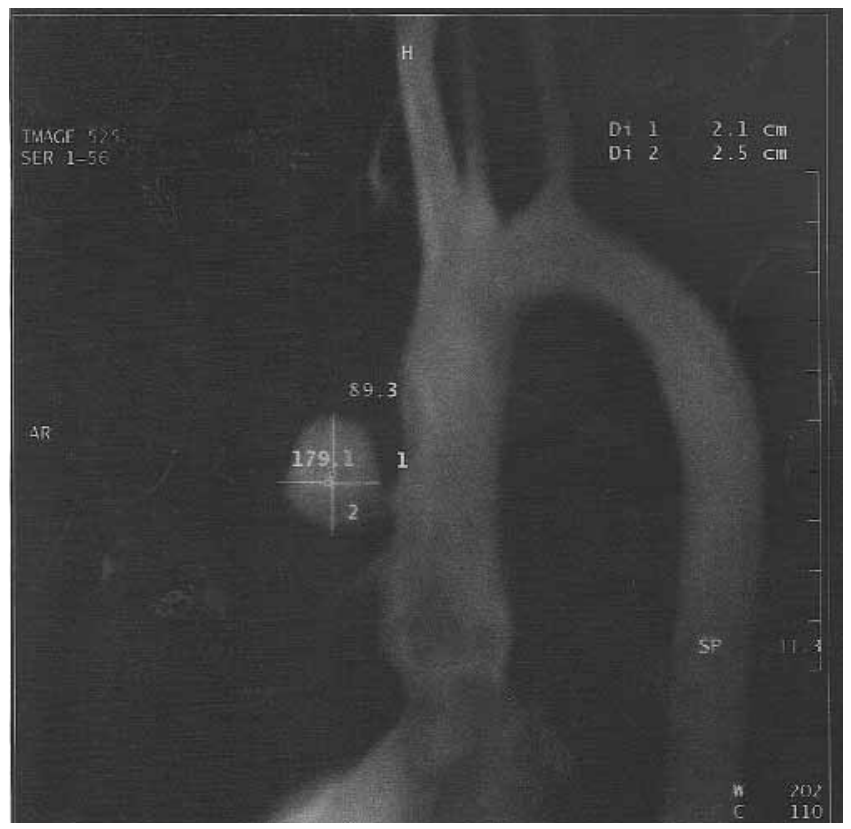

Figure 4. Postoperative magnetic resonance angiogram showed a saccular pseudoaneurysm located in the ascending aorta, $1.5 \mathrm{~cm}$ above the right coronary artery ostium.

\section{Discussion}

Behçet disease is a systemic, generalized, chronic, inflammatory disease characterized by oral aphtha, genital ulcers, and ocular lesions. Cardiac involvement is seen in approximately $5 \%$ of patients with Behçet disease, and abnormalities such as pericardi- 
tis, aortic and mitral insufficiency, and endomyocardial fibrosis have been described. Coronary artery disease in Behçet disease is extremely uncommon. ${ }^{3}$ Recurrent superficial or deep migratory thrombophlebitis develops in approximately $25 \%$ of the patients. Arterial lesions are characterized by the formation of saccular aneurysms and occlusions. ${ }^{4}$ Inflammation of small vessels is an important finding. Venous thrombosis is frequent and may lead to vena caval obstruction and even to intracardiac thrombosis. ${ }^{5}$

Surgical treatment for Behçet disease is difficult because the surgeon must handle fragile, inflamed tissue. Steroid administration to decrease inflammation preoperatively and postoperatively may be important. ${ }^{2}$

The incidence of total obstruction of the left main coronary artery in reported series ranged from $0.04 \%$ to $0.43 \%$ of all patients who underwent cardiac catheterization. ${ }^{1}$ Although the clinical presentation varies, it generally imitates severe coronary artery disease. To survive, these patients need a dominant right coronary artery and a well-developed collateral circulation. It was reported that these patients improve well and have a better prognosis after CABG.

We believe it is crucial to eliminate the possibility of coronary artery disease in patients with Behçet disease who have angina pectoris, even if they are very young. Before a surgical intervention, it is important that these patients be scanned for other system abnormalities, especially aneurysms of the aorta and its major branches. Such findings can have a radical impact on the surgical procedure to be performed. Careful manipulation of the aorta and steroid therapy may be useful to decrease the possibility of aneurysm formation. It is clear from our case that these precautions are not enough, and surgical techniques should be modified to improve the surgical outcome. To minimize aortic manipulations, no-touch techniques on the beating heart with the use of in situ arterial grafts can be recommended when possible. Patients with Behçet disease must be monitored for postoperative pseudoaneurysm formation with noninvasive methods to get good long-term results.

\section{References}

1. Shahian DM, Butterly JR, Molocoff RF. Total occlusion of the left main coronary artery. Ann Thorac Surg. 1988;46:317-20.

2. Ando M, Kosakai Y, Okita Y, Nakano K, Kitamura S. Surgical treatment of Behçet's disease involving aortic regurgitation. Ann Thorac Surg. 1999;68:2136-40.

3. Hirose H, Takagi M, Noguchi M, Miyagawa N, Narimatsu M, Yamada $\mathrm{T}$, et al. Coronary revascularization and abdominal aortic aneurysm repair in a patient with Behçet's disease. J Cardiovasc Surg (Torino). 1998;39:751-5.

4. Güler K, Kırali K, Erentuğ V, Balkanay M, Gürbüz A, Yakut C. An abdominal aortic aneurysm causing vertebral destruction in a patient with Behçet's disease. Turk J Vasc Surg. 1998;7:155-7.

5. Kırali K, Civelek A, Dağlar B, Şişmanoğlu M, Akıncı E, Berki T, et al. An uncommon complication of Behçet's disease: intracardiac thrombosis needing surgical treatment. Thorac Cardiovasc Surg. 1998;46: 102-5. 